\title{
A caatinga cantada: uma proposta de metodologia de ensino para a construção de conceitos da zoologia
}

A caatinga cantada: a teaching methodology proposal for the construction of zoology's concepts

La caatinga cantada: una propuesta de metodología de enseñanza para la construcción de los conceptos de la zoología

\section{Camila Oliveira Lourenço}

Pós-graduanda em Educação Científica e Ambiental, UFLA, Brasil camila_olourenco@hotmail.com

Luiza Helena Augusto Graduada - Licenciatura em Ciências Biológicas, UFLA, Brasil luh555@hotmail.com

Ingrid Marciano Alvarenga Pós- graduanda em Ciências Veterinárias, UFLA, Brasil dizi_alvarenga@hotmail.com

Larissa Figueiredo Salmen Seixlack Bulhões

Professora Doutora, UNESP, Brasil larissa.bulhoes@ded.ufla.br

Antonio Fernandes Nascimento Junior

Professor Doutror, UFLA, Brasil toni_nascimento@yahoo.com.br 


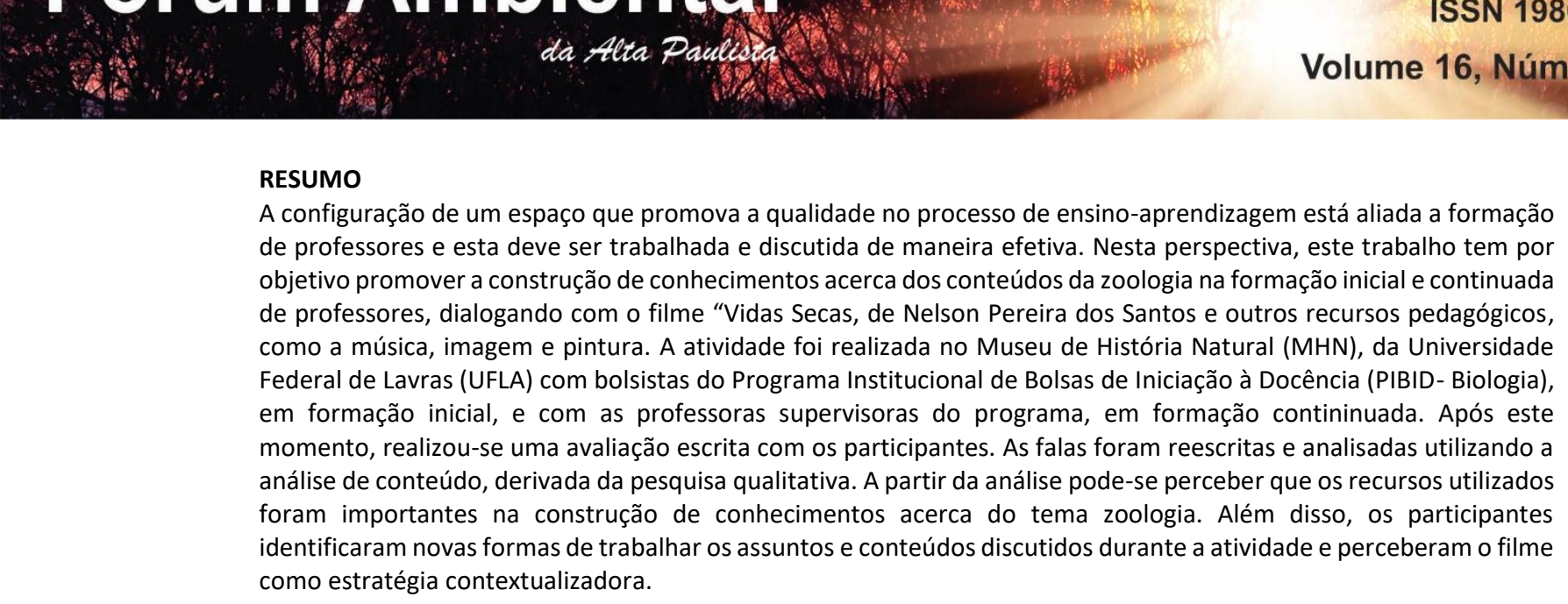

PALAVRAS-CHAVE: Recursos pedagógicos. Ensino de Zoologia. Formação Inicial e Continuada de professores.

\section{ABSTRACT}

The configuration of a space that promotes quality in the teaching-learning process is allied with teachers training and this must be effectivelly worked out and discussed. In this perspective, this work aims to promote knowledge construction about zoology's contents in the initial and continuous teachers training, dialoguing with the film "Vidas Secas" by Nelson Pereira dos Santos and other pedagogical resources, such as music, image and painting. The activity was carried out in the Natural History Museum (MHN) of the Federal University of Lavras (UFLA) with students from the Institutional Scholarship Program (PIBID-Biology), in initial formation, and with the program's supervising teachers, in continuous teachers training. After this moment, a written evaluation was realised with the participants. The speeches were rewritten and analyzed using content analysis, derived from qualitative research. From the analysis we can see that the used resources were important for the knowledge construction about zoology. In addition, the participants identified new ways of working with the discussed subjects and contents during the activity and they realized that the film can be used as a contextualizing strategy.

KEY WORDS: Pedagogical resources. The teaching of Zoology. Initial and Continuos Teacher Training.

\section{RESUMEN}

La configuración de un espacio que promueva la calidad en el proceso de enseñanza-aprendizaje, está aliada a la formación de profesores y esta debe ser trabajada y discutida de manera efectiva. En esta perspectiva, este trabajo tiene por objetivo promover la construcción de conocimientos acerca de los contenidos de la zoología en la formación inicial y continua de profesores; en dialogo con la película "vidas secas, de Nelson Pereira dos Santos y otros recursos pedagógicos, como la música, imagen y pintura. La actividad fue realizada en el Museo de Historia Natural (MHN), de la Universidad Federal de Lavras (UFLA) con becarios del Programa Institucional de Becas de Iniciación a la docencia (PIBID-Biología), en formación inicial y con las profesoras supervisoras del programa, en formación continua. Después, se realizó una evaluación escrita con los participantes. Las palabras fueron reescritas y analizadas, utilizando el análisis de contenido derivado de la investigación cualitativa. A partir del análisis, se puede percibir que los recursos utilizados, fueron importantes en la construcción de conocimientos acerca del tema zoología. Además, los participantes identificaron nuevas formas de trabajar los temas y contenidos discutidos durante la actividad y percibieron la película como estrategia para contextualización.

PALABRAS CLAVE: Recursos pedagógicos. Enseñanza de Zoología. Formación Inicial y Continuada de profesores. 


\section{INTRODUÇÃO}

A formação de professores é um assunto essencial quando tratamos de educação, pois pode ser um dos meios pelos quais ao debruçarmos com afinco e responsabilidade haverá melhorias no processo de ensino-aprendizagem (PACHECO, 2011). Porém, segundo Saviani (2009), para que haja uma mudança no processo de formação docente é necessário que consideremos as condições de trabalho dos profissionais dessa área que interferem na má qualidade de formação, fazendo com que os professores se tornem desmotivados na busca por cursos que irão auxiliá-lo. Além disso, Pacheco (2011) argumenta que, os cursos de formação de docentes necessitam de um currículo que abarca a formação do sujeito incluindo aspectos pessoais, culturais, sociais, científicos e tecnológicos, proporcionando uma ação pedagógica mais consistente acerca do ambiente em que o professor atuará.

Tratando da formação em uma perspectiva crítico- reflexiva, Nóvoa (1995) traz que, os professores serão estimulados a atuar de uma forma participativa, tendo um pensamento autônomo nos momentos de decisão. Além disso, este tipo de formação permite ao docente o desenvolvimento pessoal, profissional e criativo. Para Pimenta (1999), a formação de professores na verdade é um processo de autoformação na medida em permite a formação pessoal e profissional, além disso, ela se configura como um único projeto, partindo da formação inicial até a formação continuada dos educandos.

Segundo Cunha e Krasilchik (2005) a formação do professor não termina nos cursos de licenciatura, nem em cursos de atualizações que são realizados pelas universidades. Assim é necessária uma formação continuada no cotidiano escolar que se dê de forma constante. De acordo com Nóvoa (1995), as práticas coletivas na formação continuada de professores favorecem a discussão através dos diferentes assuntos propostos neste momento, permite analisar as diferentes problemáticas encontradas na sala de aula e promove uma iniciativa dos educandos em resolver as dificuldades encontradas no ambiente escolar.

Conforme Viégas e colaboradores (2015), tanto a formação inicial quanto da continuada de professores mostra um descompasso entre os assuntos pedagógicos e científicos. Os autores ainda trazem que, os conhecimentos científicos são privilegiados pelos cursos de licenciatura e esse é um dos aspectos que explicam a dificuldade dos professores em transpor os conhecimentos científicos adquiridos para os alunos no momento de ensino-aprendizagem nas escolas.

Tratando da área de Zoologia que, segundo Araújo-de- Almeida et al. (2009), anteriormente era definida como uma ciência que realiza apenas a pesquisa de animais, podemos perceber alguns problemas com relação ao ensino desse tema, conforme Freitas (2009 apud Santos e Téran, 2011, p. 2), apesar de ser uma área que permite a interação entre ciência, tecnologia e sociedade, proporcionando o estudo dos animais a partir de sua relação com os ecossistemas em um contexto ecológico e evolutivo.

Para Santos e Téran (2009), esses problemas estão aliados ao uso exclusivo do livro didático no ensino de zoologia, a defasagem dos professores com relação aos conceitos zoológicos, a falta de recursos pedagógicos no ensino, bem como a ausência de laboratórios e espaços não formais que auxiliam no processo de ensino-aprendizagem e o tempo reduzido para o planejamento e 
aplicação das atividades em sala de aula. Além disso, é uma área que sofre com a falta de contextualização, assim ela é vista como desatualizada, conforme Amorim (2005).

A limitação no momento de contextualizar os conceitos zoológicos também é trazida no Parâmetro Curricular Nacional (BRASIL, 1998), assim o documento aborda que no ensino dos conceitos zoológicos é discutido temas como a classificação, a anatomia e a fisiologia comparadas sem considerar que os organismos interagem entre si e além disso estão associados a um ambiente. Neste momento também não é vislumbrada as questões evolutivas envolvidas, o uso sustentável da biodiversidade encontrada na terra, a expansão agrícola e então os saberes essências para a prática do indivíduo como cidadão é deixada a margem.

Pensando nas problemáticas trazidas com relação ao ensino-aprendizagem na área de Zoologia, podemos compreender conforme Bastos Junior (2013) que, ao longo da história da educação houve modificações com relação aos métodos de ensino utilizados nas instituições escolares e isso se deu devido as transformações sociais, histórias e políticas em que a sociedade vêm passando. Atualmente, ainda segundo o autor, os professores de ciências podem encontrar uma série de alternativas metodológicas que irão auxiliar sua prática.

O cinema surge como uma dessas ferramentas alternativas. Ele, segundo Nascimento (2004), se configura como uma linguagem artística há mais de cem anos se tornando um recurso utilizado há muito tempo no processo de ensino-aprendizagem, pois muitos intelectuais da Escola Nova, em 1930, percebiam seu potencial em direção a educação. Além disso, segundo Abud (2003), a utilização desse recurso pedagógico em sala de aula tem sido facilitada pelas políticas públicas de incentivo a comunicação. Porém a forma que ele é trabalhado na sala de aula precisa ser elaborada e estrutura afim de realizar uma avaliação crítica da história desse meio de comunicação (NASCIMENTO, 2004).

Apesar das dificuldades encontradas com relação a utilização desse recurso, Abud (2003) traz que, ele deve ser trabalhado nas escolas, pois promove ao estudante perceber as relações existentes no mundo entre o meio social e cultural, permite desenvolver estratégias de exploração do local onde o indivíduo vive, estabelecer relações socais, além disso permite ao aluno observar, identificar e posteriormente realizar comparações e articulações no mundo em que vive.

A arte e a ciência também se configuram como uma das possibilidades de metodologias que auxiliam no processo de ensino-aprendizagem, pois de acordo com Massarani e colaboradores (2006) esses elementos fazem parte da criação do ser humano e é por onde ele pode expressarse individualmente ou coletivamente demostrando e compartilhando os conhecimentos adquiridos ao longo da sua vida. Porém, os autores ainda trazem que o avanço científico promoveu modificações nas manifestações artísticas de todos os tipos, na pintura, nas artes cênicas e músicas.

Neste sentido, podemos perceber a música como uma linguagem alternativa lúdica que permite o ensino na área de ciências e biologia, pois segundo Oliveira e colaboradores (2011), exercitar a prática de ouvir a música ultrapassa a questão de análise do seu conteúdo, permitindo ao estudante ou ouvinte ampliar seus conhecimentos no âmbito cultural, fortificando seu espírito crítico e criativo. 
Para Massarani e colaboradores (2006), a realização de análise das letras de músicas populares com conteúdo científico também é um processo que se torna importante na sala de aula na medida em que motiva os estudantes no processo de ensino-aprendizagem e promove a construção de conhecimentos de forma interdisciplinar. Além disso, segundo Martins e colaboradores (2009), a música promove ao ouvinte relembrar acontecimentos da sua vida e isso permite explorar as emoções dos indivíduos e por apresentar três linguagens distintas, a literomusical, musical e verbal, ela exige uma competência de quem escuta para que possam ser feitas análises coerentes sobre seus aspectos e conteúdos, nesse momento, cabe ao professor como mediador do processo de ensino, intervir na prática de compreensão das músicas.

A imagem se configura como outra alternativa pedagógica para o ensino de ciências e biologia. Para Tomio e colaboradores (2013), esse recurso não deve ser considerado meramente transmissão de informações, mas como parte de um processo abrangente de produção e reprodução de sentidos colocados por ela e para isso é preciso que haja uma interação entre a imagem e o sujeito que está analisando-a, considerando suas particularidades e o contexto em que essa alternativa metodológica está inserida. Cumming (1995) traz, especificamente, a pintura como um meio de viajar por um novo ambiente e se familiarizar com ele, fazendo com que o indivíduo tenha novas percepções sobre o que foi visualizado, mas para o autor é necessária uma preparação anterior a esse momento. Nessa perspectiva, Carneiro e colaboradores (2003) acreditam que, as imagens exercem um papel importante no ensino, sendo relevantes utiliza-las durante as aulas de ciências e biologia, desde que, sejam exploradas juntamente como o auxílio do professor.

Assim, o presente trabalho tem por objetivo promover a construção de conhecimentos acerca dos conteúdos da Zoologia, especificamente conceitos de Classificação, Origem dos grupos e Evolução, Adaptações, Interações, Extinção e Conservação dos animais, na formação inicial e continuada de professores, dialogando com o filme "Vidas Secas, de Nelson Pereira dos Santos e recursos pedagógicos como a música, imagem e pintura. Além disso, descontruir com os alunos o estereótipo da "seca" presente no bioma caatinga. Para a elaboração da atividade foi proposta a realização de um minicurso que atuasse na formação inicial e continuada de professores.

\section{METODOLOGIA}

A metodologia utilizada foi a pesquisa qualitativa que, segundo Tozoni-Reis (2007), é um tipo de pesquisa que pretende compreender os conteúdos dados pelos fenômenos sociais que não podem ser quantificados. Além disso, segundo Minayo (1999), este tipo de pesquisa envolve a participação de diversos sujeitos e abrange o ambiente em que estes estão inseridos, assim várias são as possibilidades de interação no momento da pesquisa.

Após o desenvolvimento da atividade foram realizadas avaliações por escrito com os estudantes. A interpretação das falas foi realizada a partir do método de análise de conteúdo. Dentro deste tipo de análise utilizamos o parâmetro de categorização das falas. Esta metodologia foi adotada a fim de investigar de forma mais ampla as percepções dos participantes uma vez que, a categoria agrupa elementos, ideias, expressões que contém semelhhanças e assim podem ser investigadas e interpretadas. (MINAYO, 1999). 


\section{DESCRIÇÃO DO MINICURSO}

A proposta de trabalho foi desenvolvida para a disciplina Metodologia do Ensino em Zoologia, no ano de 2015, na Universidade Federal de Lavras (UFLA), Minas Gerais. E realizada no Museu de História Natural (UFLA).

Inicialmente foi proposto que os estudantes assistissem o filme Vidas Secas, Nelson Pereira dos Santos. A partir disso foram realizadas indagações aos alunos dos elementos que foram marcantes visualizados no filme. Eles trouxeram a questão da seca, percebendo a caatinga como um ambiente desfavorável para produção de alimentos e sobrevivência dos animais e a dificuldades encontradas pelas famílias em viver naquele ambiente, pois a família retratada no filme buscava meios de sobreviver a todo momento. Assim foi possível discutir os aspectos sociais, culturais e biológicos que o filme abarcava, além de trazer uma outra visão de cinema aos estudantes. Após a visualização do filme atividade se desenvolveu em alguns momentos.

No primeiro momento foi realizada uma dinâmica com os estudantes. As ministrantes colocaram o som característico que pode ser ouvido pelos carros de boi e pediram aos participantes para que fechassem os olhos e escutassem com atenção o som evidenciado. Após esse momento, foi apresentada a música Lamento Sertanejo, interpretada por Gilberto Gil e Dominguinhos, juntamente com a pintura Naif "Os Retirantes", da artista pernambucana Rosângela Borges.

A partir desses elementos foi questionado qual seria a relação da pintura, da música e do som de carro de boi com o filme Vidas Secas. Os estudantes discutiram, a partir dos recursos, trazendo elementos visualizados no filme como a seca, o bioma caatinga, a família de Fabiano como representante dos retirantes percebidos na pintura naif.

No segundo momento da prática foi apresentada a música o Canto da Ema, interpretada por Zé Ramalho, e os participantes foram questionados o porquê a Ema estar representada na música e se o animal teria alguma ligação com o cenário do filme. As responsáveis pelo minicurso fizeram uma série de questionamentos e então os estudantes chegaram a resposta de que a Ema é um dos animais presentes na caatinga.

Percebendo então a ema como animal pertencente à fauna da caatinga, foi indagado aos participantes se estes conheciam outras músicas com animais característicos desse bioma. Após este questionamento foram mostradas algumas fotografias de animais característicos do ambiente.

Posteriormente os alunos foram divididos em cinco grupos, cada um ficou com dez fotograficas de animais pertencentes aos cinco grupos (Peixes, Anfíbios, Repteis, Mamíferos e Aves) para que os discentes classificassem estes animais de acordo com um critério elaborado por eles.

Após a construção dos critérios de classificação pelos estudantes pode-se perceber que a maioria dos grupos classificaram a partir de seus conhecimentos prévios. Outro grupo fez a classificação pela quantidade de patas ou ausência delas, e o restante dos grupos realizou a classificação seguindo as características físicas dos animais representados nas fotos. Posteriormente foi discutida a importância de se classificar os animais, utilizando uma analogia com as prateleiras dos supermercados e da biblioteca, para explicar como se configura a classificação dos animais. 
Ainda tratando da questão classificação dos animais foi apresentada a música Azulão, interpretada por Maria Bethânia e com base na sua letra as ministrantes questionaram os participantes se o animal representado pela música sempre teve como habitat a caatinga. Também levantaram a questão se aqueles animais vislumbrados nas fotografias sempre tiveram a mesma anatomia. Com isso, os alunos puderam perceber que houve uma evolução do grupo e assim os indivíduos conseguiram persistir no ambiente. Então, pode-se construir conhecimentos com relação ao conceito de origem e evolução dos grupos.

Para a construção do conceito de adaptação foi utilizada a música Acauã, interpretada por Elba Ramalho. Os participantes foram questionados se aqueles animais representados na música que, também tem a caatinga como habitat, poderiam sobreviver em outros biomas, ou se animais de outros biomas poderiam sobreviver na caatinga. Com base nesses questionamentos, os alunos responderam que sim, os animais poderiam sobreviver em outros biomas, porém não obteriam respostas tão satisfatórias quanto aos animais que já são adaptados no ambiente.

Posteriormente, com o objetivo de construir o conceito de Interação foram apresentadas duas músicas, Penas de Tié, interpretada por Maria Bethânia e Omara Portuondo e Carcará também interpretada por Maria Bethânia. Nesta etapa as prelecionistas realizaram questionamentos em direção à qual seria a relação entre os animais tratados na música. A partir disso, foi possível construir junto como os estudantes que todos os seres vivos interagem entre si e são dependentes um dos outros, podendo ser interações positivas ou até mesmo negativas como foi abordado o conceito de predação como interação negativa na música Carcará como foi mostrada na música carcará, a predação.

A músicas Saga da Amazônia, interpretada por Vital Farias e Caatinga Floresta Branca, interpretada por Toninho Arcoverde e o poema O lamento do juriti, declamado por Onildo Barbosa foram utilizados para discutir as questões do desmatamento, extinção das espécies e suas causas, a caça ilegal de animais silvestres, contrabando e venda desses animais, as queimadas e a degradação do habitat natural, assim foi possível discutir com os estudantes a importância da preservação da fauna e flora da caatinga, visto que o bioma é exclusivamente brasileiro, rico em biodiversidade e cultura. Então, foi possível abarcar o tema Extinção e Conservação na medida em que os discentes traziam possíveis soluções para a preservação ambiental do bioma.

Ao final da atividade as prelecionistas trouxeram uma reportagem que trazia informações sobre os Jumentos, animais bem característicos da caatinga. O texto abordava a negligencia com relação a estes animais com estes animais que durante anos auxiliavam os agricultores rurais em seu trabalho e nos dias de hoje estão sendo abandonados e trocados por máquinas. Assim foi trazido que, uma organização de proteção animal da região, juntamente com outros colaboradores criaram o Santuário dos Jumentos, um local de reabilitação, proteção e descanso desses animais, que é um dos ícones da cultura nordestina.

\section{RESULTADOS E DISCUSSÃO}

Como método avaliativo da atividade foi realizada um questionamento aos participantes, indagando como a prática desenvolvida contribuiu para sua formação. As falas categorizadas abaixo (Quadro 1) foram transcritas da avaliação escrita da atividade desenvolvida na disciplina 
Metodologia do Ensino em Zoologia. Foi orientado aos participantes para que não se identificassem com nomes durante esse processo. As falas alunos estão identificados pela letra " $A$ " e a falas das professoras participantes estão identificadas com a palavra professora, seguida de uma numeração de acordo com a ordem das falas. Durante o momento de discussão algumas falas dos participantes foram escolhidas com o intuito de representar cada categoria.

\section{Quadro 1: Categorização das falas}

\begin{tabular}{|c|c|c|}
\hline Categorias & Descrição & Frequência \\
\hline Recursos pedagógicos & $\begin{array}{l}\text { Nesta categoria estão inseridas } \\
\text { as falas dos participantes de } \\
\text { formação inicial e continuada } \\
\text { que tratam da possibilidade do } \\
\text { minicurso em aumentar o } \\
\text { reportório acerca dos recursos } \\
\text { pedagógicos e trazer as } \\
\text { possibilidades destes na } \\
\text { construção de conhecimentos. }\end{array}$ & 12 \\
\hline $\begin{array}{c}\text { Conceitos estruturantes para a } \\
\text { zoologia }\end{array}$ & $\begin{array}{l}\text { Esta categoria apresenta falas } \\
\text { dos professores em formação } \\
\text { continuada e inicial que tratam } \\
\text { da possibilidade do minicurso } \\
\text { em construir conhecimentos } \\
\text { acerca do tema zoologia. }\end{array}$ & 5 \\
\hline Visão da Caatinga & $\begin{array}{l}\text { Nesta categoria estão inseridas } \\
\text { as falas dos estudantes em } \\
\text { formação inicial. Elas abordam a } \\
\text { nova visão construída acerca do } \\
\text { bioma caatinga após o } \\
\text { desenvolvimento do minicurso. }\end{array}$ & 5 \\
\hline O uso do filme & $\begin{array}{l}\text { Esta categoria também agrupa } \\
\text { falas dos estudantes em } \\
\text { formação inicial e traz a ideia do } \\
\text { filme como recurso a ser mais } \\
\text { explorado durante o } \\
\text { desenvolvimento da atividade. }\end{array}$ & 3 \\
\hline
\end{tabular}

A categoria recursos pedagógicos traz a importância da diversidade de ferramentas que irão auxiliar na formação de professores. Podemos perceber esse aspecto na fala do participante A12 e Professora 1:

A12- Gostei da diversidade de musicas tocadas e selecionadas, enriqueceu meu leque de musicas que relacionam o habitat caatinga, a biodiversidade da fauna com as relações humana. Minha formação ficou mais robusta acerca do nordeste...

Professora 1- A pratica contribuiu com a construção do uso da imagem, da música do espaço.

A educação e comunicação foram aspectos que se intensificaram na época de 1930 com o movimento da Escola Nova, neste momento podemos identificar uma inquietação dos 
envolvidos com a área de educação com relação aos métodos e recursos pedagógicos utilizados. E a partir do século XX a união entre os novos conhecimentos e a educação torna indispensável a presença de recursos didáticos no processo de ensino-aprendizagem (VISCOVINI E COLABORADORES, 2009).

Os educandos devem saber da importância da utilização dos recursos pedagógicos como auxiliadores no ensino -aprendizagem dos estudantes, segundo Souza (2007). Para isso, eles devem ter uma formação adequada para que possam utilizar desses recursos, percebendo as razões da utilização destes na construção do ensino-aprendizagem e essa percepção só ocorrerá em um processo de formação que prepare o docente para as determinadas competências. Além disso, a autora traz a importância de construir um recurso que esteja embasado em uma teoria de educação ou acompanhado de uma reflexão pedagógica para que possa cumprir seu papel no ensino.

Outro fator que se mostra essencial a prática do professor é conhecer as potencialidades dos recursos para que seu uso não resulte no que é chamado de "inversão didática". Neste momento, o material didático passa a ser visto como isolado do processo de ensino e ganha um caráter de estudo por si mesmo (SOUZA, 2007). Porém, conforme Valente (1999), é necessário que se crie condições ao professor em formação para que este possa recontextualizar seu aprendizado e as experiências vivenciadas, durante o seu processo de formação, para a realidade escolar, vislumbrando as possíveis necessidades dos estudantes, além de colocar em prática os objetivos pedagógicos que sua prática se propõe cumprir.

Além disso, esta categoria abarca as falas que tratam da importância dos recursos didáticos na construção de conhecimentos. Essa ideia pode ser percebida na fala de A2 e da Professora 2, descrita abaixo.

A2- A prática trouxe com riqueza musicas que podem possibilitar a construção de conceitos relacionados à zoologia...

Professora 2-...consegui perceber que existe muitas formas de trabalhar um bioma através da arte, música. Deixando as aulas sempre prazerosa.

Segundo Santos e Silva (2013), a utilização de aulas expositivas e não participativas pode apresentar algumas dificuldades durante o processo de ensino-aprendizagem. Para os autores trabalhar com esses métodos faz com que o educando se torne um sujeito passivo na ação de aprender, pois nesse momento ele se torna um ouvinte de informações passadas pelo educador, sem participar das discussões que o cerca, assim sua aprendizagem torna-se pouco significativa. Nesta perspectiva, os mesmos autores trazem os recursos pedagógicos como forma de solucionar as dificuldades com relação ao processo de ensino (SANTOS E SILVA, 2013).

De acordo com Viscovini e colaboradores (2009), a ausência de recursos didáticos causa uma dificuldade com relação ao ensino de determinados conteúdos, principalmente na área de ciências naturais, assim, segundo os autores é necessário um incentivo governamental para que seu uso seja ampliado e posteriormente mais utilizado nas escolas, pois esses materiais 
permitem compreender os conteúdos científicos e relaciona-los com a realidade do estudante. Porém, ainda conforme o autor, não basta só utilizar os recursos pedagógicos como auxiliadores na construção de conhecimentos é necessário que o docente tenha um compromisso constante na aplicação desses materiais, refletindo sobre como esse meio pode promover a construção de conhecimentos (VISCOVINI E COLOBORADORES, 2009).

Oliveira e Trivelato (2006) trazem que, o uso dos mais variados recursos e estratégias pedagógicas utilizadas no processo de formação de professores permite solucionar a falta de interação entre professores, alunos, recursos pedagógicos e os conhecimentos proporcionados durante essas interações. Para que isso seja possível, o processo de formação deve priorizar a mudança de metodologias utilizadas e adotar novos procedimentos que irão auxiliar uma formação docente mais sólida, no sentido em que permite o professor realizar uma reflexão da sua própria prática (OLIVEIRA E TRIVELATO, 2006).

A categoria conceitos estruturantes da zoologia abarca falas dos professores em formação inicial e continuada, abordando a possibilidade do minicurso em construir conhecimentos acerca do tema zoologia. As falas que retratam esses conteúdos estão descritas abaixo.

A9- ..Permite construir conceitos biológicos (adaptação, biomas), pensar no contexto na caatinga e riqueza. Entender processos de classificação biológicas, trabalhar educação ética ambiental, através das queimadas, parque ecológicos (conservação).

Professora 3- A pratica contribuiu para se conhecer grupos de animais do nordeste com suas características adaptativas ambientais e evolutivas.

Conforme Bastos Junior (2013), os cursos de graduação, tradicionalmente trazem os conhecimentos acerca do tema zoologia de uma maneira descritiva, tratando os animais agrupados em categorias taxonômicas ou didáticas, além de abordarem as características morfológicas e fisiológicas dos organismos. Além disso, as estratégias utilizadas nestes cursos expõem o conteúdo a ser ensinado e ainda se baseia na aplicação de aulas práticas para apresentação de animais vivos e não vivos.

Segundo Fernandes (1997), a forma de ensinar zoologia nas escolas básicas, também de forma descritiva e descontextualizadora, pode ter relação com a forma em que os professores de biologia são formados, assim estes reproduzem os métodos utilizados pelas instituições onde foram formados, incorporando uma ação pedagógica que reprodução não só as metodologias apreendidas, mas também os conteúdos e conhecimentos biológicos. Assim, os estudantes da educação básica veem a zoologia como uma disciplina que só apresenta diversos nomes científicos, ciclos e tabelas a serem memorizados, desconsiderando a importância dessa área na sua formação cidadã. Neste sentido, o autor traz recursos pedagógicos como os filmes e as imagens, os quais foram utilizados no desenvolvimento do minicurso tratado neste trabalho, como auxiliadores na aprendizagem dos conteúdos zoológicos.

A categoria visão da caatinga trazem falas que abordam a percepção dos alunos acerca de uma nova caatinga, através das discussões realizadas durante a atividade. Podemos identificar esse aspecto na fala de A5: 
A5- O minicurso foi de grande ajuda para a construção de uma caatinga diferente em meus pensamentos. Vejo agora que este bioma possui muitas mais riquezas do que eu pensava.... Além de toda uma diversidade da fauna presente e única.

Segundo Araújo e Sobrinho (2009), quando tratamos do bioma caatinga nossas falas estão entremeadas de preconceitos, porém os indivíduos não conhecem e compreendem a realidade da região. Esses preconceitos e falta de conhecimento podem ser identificados até mesmo na prático do professor ao tratar do bioma caatinga. Para Nascimento Junior e colaboradores (2016) é necessário que os professores reconheçam esse bioma como rico e diverso, podendo trabalhar através dele diferentes aspectos, como os biológicos, geológicos, culturais e sociais. Ainda de acordo com os autores, os minicursos tornam-se importantes para que os futuros professores desconstruam os estereótipos que circundam o bioma e a população que vive nesse ambiente.

Segundo Alves e Oliveira (2016) é necessário despertar nos docentes a importância de se trabalhar o bioma caatinga nas escolas para que os estudantes possam reconhecer as principais espécies da flora e flora dessa região, atuando de forma a preservar este ambiente rico, diverso e com características marcantes e específicas. Assim, as discussões sobre este bioma nos permitem trazer a educação ambiental como instrumento fundamental neste momento, pois ao trabalhar com o bioma caatinga é necessário uma discussão e comprometimento da sociedade. Neste momento, o indivíduo procura participar ativamente da resolução de problemas que permeiam sua realidade e o contexto em que ele vive.

A categoria uso do filme aborda as falas tratando a ausência no filme durante a atividade desenvolvida, além disso, os participantes trouxeram que o filme poderia ser mais explorado. Podemos perceber esses aspectos nas falas abaixo.

A3-... f filme podia ser um pouco mais explorado, contribuindo mais para a construção da metodologia.

Conforme Fonseca (2004) é relevante que o professor se prepare previamente para que sua atuação em sala de aula seja coerente e clara, afim de atingir os objetivos propostos para que haja um entendimento dos estudantes. Tratando, especificamente, da utilização do filme o autor ainda traz a importância da preparação prévia e do domínio do professor com relação aos filmes, pois este deve ter em mente o objetivo de utilizar a ferramenta e elaborar maneiras de trabalhar os assuntos e conteúdos trazidos pelo filme.

O objetivo da utilização de filmes deve estar baseado na facilitação do processo de ensinoaprendizagem, pois ele se torna uma opção motivadora e interessante, uma vez que não se torna meramente ilustrativa e que não substitua o papel do professor, mas se configura como meio audiovisual que promove uma reflexão sobre os temas colocados (ALMEIDA, 1994). Porém, ainda de acordo com o autor, torna-se um desafio ao educador estimular a visualização e discussão dos filmes no ambiente escolar, trazendo não só os aspectos que abarcam conceitos 
e conhecimentos

das

disciplinas

escolares,

mas

os

valoresculturais, sociais e ideológicos de uma sociedade que diversos filmes abordam.

\section{CONSIDERAÇÕES SOBRE A PRÁTICA}

Após a análise das falas dos participantes pode-se perceber que os recursos utilizados durante a atividade contribuíram para a construção de conhecimentos acerca do tema zoologia, além disso a apresentação dos diversos recursos didáticos permitiu aos professores em formação inicial e continuada pensar sobre a utilização dos recursos em suas aulas.

Outro aspecto identificado foi a modificação dos participantes com relação a visão de paisagem da caatinga, assim, pode-se identificar a desconstrução de conceitos sobre o bioma com relação a seca e a baixa diversidade da região. Além disso, foi possível abarcar a cultura nordestina, possibilitando aos participantes uma reflexão acerca dos elementos do assunto. Também perceber-se a importância de utilizar os filmes durante a atividade, compreendendo o objetivo de inserir essa ferramenta nos seus mais diversos aspectos e discuti-lo de forma aprofundada, trazendo os elementos sociais, culturais e políticos que permeiam esse meio.

\section{AGRADECIMENTO}

\section{CAPES}

\section{REFERÊNCIAS BIBLIOGRÁFICAS}

ABUD, Katia Maria. A construção de uma didática da História: algumas idéias sobre a utilização de filmes no ensino. História (São Paulo), São Paulo, v. 22(1), p. 183-193, 2003.

ALMEIDA, Milton José de. Imagens e Sons: A nova cultura oral. São Paulo: Cortez, 1994

ALVES, Telma Gomes Ribeiro; OLIVEIRA, Jorge Miguel Lima. A percepção dos alunos do Ensino Médio sobre o bioma da caatinga. Anais III Congresso Nacional Educação (CONEDU), v. 1, p. 01, 2016.

AMORIM, Dalton. de. Souza. Paradigmas, espécies ancestrais e o ensino de Zoologia e Botânica. Metodologia de ensino de disciplinas da área de Ciências da Natureza, Matemática e suas tecnologias do ensino médio: Física, Química e Biologia. Teia do Saber, 2005.

ARAÚJO, Carla Souza; FALCAO SOBRINHO, João. O Bioma Caatinga no Entendimento dos Alunos da Rede Pública de Ensino da Cidade de Sobra I(CE). Revista Homem, Espaço e Tempo, v. 1, p. 24-51, 2009.

ARAÚJO-DE-ALMEIDA, Elineí. Construção de conhecimentos em Zoologia: uma interação entre o científico e o lúdico. In: ENCONTRO NACIONAL DE PESQUISADORES EM EDUCAÇÃO EM CIÊNCIAS (ENPEC), 7, Florianópolis, 2009.

BASTOS JUNIOR, Pedro de Souza. Metodologias e estratégias para o ensino de zoologia. 2013. Monografia. Universidade de Brasília (UnB), Faculdade UnB, Planaltina - DF.

Brasil, Parâmetros Curriculares Nacionais: ciências naturais. Secretaria de Educação Fundamental. Brasília, DF: MEC/SEF, 1998.

DIB, Siland Meiry; MENDES, Jaqueline Ribeira de Souza; CARNEIRO, Maria Helena da Silva. Texto e imagens no ensino de ciências. In: ENCONTRO NACIONAL DE PESQUISA EM EDUCAÇÃO EM CIÊNCIAS, 4., 2003, Bauru. Anais do Encontro Nacional de Pesquisa em Educação. Bauru: APRAPEC, 2003.

CUMMING, Robert. Para entender a arte. São Paulo: Ática, 1995. 
CUNHA, Ana Maria de Oiveira; KRASILCHIK, Myriam. A formação continuada de professores de ciências: percepções a partir de uma experiência. São Paulo, 2005.

FERNANDES, Hylio Laganá.. Um naturalista na sala de aula. Ciência \& Ensino. Campinas, Vol. 5, 1998.

FONSECA, Claudia Chaves. Os meios de comunicação vão à escola? Belo Horizonte: Autêntica/F CHFUMEC, 2004.

MARTINS, Noara. Bolza.; SCHUTZ, Marta Dinarte.; RIGO, Mateus; TROIAN, Ana; RANGEL, Eliane de Fátima Manenti. A utilização da música como prática de ensino nos livros didáticos. Vivências (URI. Erechim), v. 5, p. 77-83, 2009.

MASSARANI, Luisa; MOREIRA, Ildeu de Castro; ALMEIDA, Carla. Para que um diálogo entre ciência e arte? Hist. cienc. saude-Manguinhos, Out 2006, vol.13, p.7-10.

MINAYO, Maria. Cecília. de. Souza.. o desafio da pesquisa social. In: (Org.) Pesquisa Social: Teoria, Método e Criatividade. 14. ed. Ed. Vozes; Petrópolis, 1999.

NASCIMENTO JUNIOR, Antonio Fernandes ; VERÍSSIMO E SILVA, Luiz Gustavo; ANDRADE, Samara Mendes Moreira; SANTOS, Ana. Flávia. . Vidas secas e a formação inicial de professores: a ecologia de paisagens, a caatinga e a cultura sertaneja ganham imagem e voz na obra de nelson pereira dos santos. Revista da SBEnBIO, v. 9, p. 5378-5389, 2016.

NASCIMENTO, Jairo Carvalho do. MINI-CURSO - "Cinema e o ensino de História: orientações metodológicas" (c/h 6 horas). In: ENCONTRO ESTADUAL DE HISTÓRIA DA ANPUH: "HISTORIADOR, A QUE SERÁ QUE SE DESTINA?, 2 , UEFS, Feira de Santana, BA.. 2004.

NÓVOA, Antonio. Os professores e a sua formação. Lisboa: Dom Quixote, 1995. NóVOA, A. (Org.). Formação de professores e profissão docente. In: NÓVOA, (ORG.). OS PROFESSORES E SUA FORMAÇÃO. Lisboa: Publicações Dom Quixote, 1995, p.13-33.

OLIVEIRA, Danielle Britto Guimarães de. O ensino de Zoologia numa perspectiva evolutiva: análise de uma ação educativa desenvolvida com uma turma do Ensino Fundamental. In: ENCONTRO NACIONAL DE PESQUISADORES EM EDUCAÇÃO DE CIÊNCIAS (ENPEC), no8, p.01-12, 2011, Campinas.

PACHECO, João Augusto. Currículo e gestão escolar no contexto das políticas educacionais. In: GESTÃO DA EDUCAÇÃO, CURRÍCULO E INOVAÇÃO PEDAGÓGICA. Recife: Universidade Federal de Pernambuco: Secretaria de Educação do Estado de Pernambuco, 2011. 14f. 1- 14.

PIMENTA, Selma Garrido. Formação de professores: identidades e saberes na docência. In: Saberes pedagógicos e atividade docente. São Paulo: Cortez, 1999. p. 15-34.

SANTOS, Ovídia Kaliandra Costa; BELMINO, José Fransdavid Barbosa. Recursos didáticos: Uma melhoria na qualidade da aprendizagem. 2013. Monografia. Graduação em Pedagogia - Faculdade Evangélica Cristo Rei, FECR, 2013.

SANTOS, Saulo Cezar Seiffert; TERAN, Augusto Fachín. Possibilidades do uso de analogias e metáforas no processo de ensino aprendizagem de Zoologia no 7ํano do ensino fundamental. In: CONGRESSO NORTE NORDESTE DE ENSINO DE CIÊNCIAS E MATEMÁTICA, 8. Boa Vista, 2009.

SAVIANI, Demeval. Formação de professores: aspectos históricos e teóricos do problema no contexto brasileiro. Revista Brasileira de Educação, v. 14, p. 143-155, 2009.

SOUZA, Salete Eduardo de. 0 uso de recursos didaticos no ensino escolar. In: SEMANA DA PEDAGOGIA DA UEM, 8 , 2007, Maringá. Anais “Infância e Práticas Educativas”. Maringá: UEM, 2007. p. 1-5.

TOMIO, Daniela et al. AS IMAGENS NO ENSINO DE CIÊNCIAS: O QUE DIZEM OS ESTUDANTES SOBRE ELAS?. Caderno Pedagógico, v. 10, n. 1, 2013.

TOZONI-REIS, Marília. Freitas de Campos.Metodologia de Pesquisa Científica. 2 ed. Curitiba: IESDE Brasil S.A, 2007. 
TRIVELATO, Silvia Luiza Frateschi; OLIVEIRA, Odisséa Boaventura de. Práticas docente: o que pensam os professores de ciências biológicas em formação. Artigo apresentado no XIII Encontro Nacional de Didática e Prática de Ensino. Rio de Janeiro, 2006.

VALENTE, José Armada. O computador na sociedade do conhecimento. Campinas: Núcleo de Informática Aplicada á Educação - Nied, 1999. 116p. p. 99-115.

VIÉGAS, Ana Luiza da Cruz; CRUZ, Lílian Mara Dela; MENDES, Ana Paula Faustino Tieti. Formação de Professores em Ciências Biológicas: Desafios, Limites e Possibilidades. Revista UNOPAR Científica - Ciências Humanas e Educação, Londrina, v.16, n.5, p. 507-519, 2015.

VISCOVINI, Ronaldo Celso; GOZZI, Maria Estela. ; ARIAS, Carmem ; MIRANDA, Débora Patrícia ; SIGOLI, Letícia dos Santos Marangoni; ZANQUETTA, Vanessa de Araújo. Recursos Pedagógicos e atuação docente. In: Congresso Nacional de Educação - EDUCERE, 9 2009, Curitiba-PR. IX Congresso Nacional de Educação - EDUCERE, 2009. 